\title{
SAMPAIO, Maria da Luz. Da fábrica ao museu: identificação, patrimonialização e difusão da cultura técnico-industrial. Lisboa: Caleidoscópio, 2017.375 p.
}

\author{
Olivia Silva Nery* \\ *Pontifícia Universidade Católica do Rio Grande do Sul - Porto Alegre, RS, Brasil \\ Doutoranda em História (bolsista Capes/PDSE processo n 88881.189962/2018-01) \\ olivianery@gmail.com \\ https://orcid.org/0000-0003-0114-9627
}


A obra de Maria da Luz Sampaio é resultado da sua investigação de doutorado em História e Filosofia da Ciência, especialidade Museologia, na Universidade de Évora, Portugal, concluída em 2015. A autora é pesquisadora da área de patrimônio e história técnico-industrial, especialista em Museologia Social e mestre em Estudos Locais e Regionais.

O livro, organizado em quatro capítulos, apresenta uma somatória de referências bibliográficas sobre patrimônio técnico-industrial, tornando-se uma leitura indispensável para os investigadores da área. A obra pertence à coleção Estudos de Museus, parceria entre a Direção-Geral do Patrimônio Cultural de Portugal e a editora Caleidoscópio. Trata-se de um digno exemplo de adaptação de tese para livro, pois sua leitura é fluida, porém não deixa de expor as questões metodológicas e teóricas imprescindíveis em uma obra científica de qualidade.

Uma das questões desenvolvida por Luz durante toda a sua obra, e aprofundada no último capítulo, é o valor que os patrimônios industriais móveis possuem para o campo, destacando a relevância de acompanhar as suas histórias e ciclos de vida. Sendo o olhar para o patrimônio industrial mais focado nos vestígios arquitetônicos, Sampaio clama para que os objetos, que também representam memoriais fabris, não sejam esquecidos e negligenciados (p. 12).

A autora inova ao trabalhar com uma temática que ainda não adquiriu o mesmo status de outros exemplares do patrimônio cultural e, ainda, focaliza no que também sai do usual: objetos técnico-industriais. Para tanto, Sampaio analisa um motor elétrico pertencente ao acervo do Museu da Indústria do Porto e demonstra de que forma a análise feita a partir de um objeto pode apresentar a convergência de fatores importantes de contextos industriais, econômicos e sociais de uma região ou país.

Introdução e primeiro capítulo demonstram as mudanças sofridas no campo do patrimônio cultural e que contribuíram para direcionar os olhares de seus agentes e investigadores para a relevância do patrimônio industrial. Dialogando com teóricos de diferentes lugares do globo, faz com que os trechos identifiquem e mapeiem as publicações mais relevantes sobre patrimônio cultural e suas respectivas contribuições e limitações.

No primeiro capítulo a autora demonstra de que forma a patrimonialização do passado industrial ocorreu na Europa e Estados Unidos, analisando exemplos de cada país. Ao conceitualizar arqueologia e patrimônio industrial 
Sampaio apresenta as semelhanças entre as duas áreas e de que forma essas discussões contribuem com pontos de vista distintos para a ciência.

A autora faz uma retrospectiva do cenário português no patrimônio industrial, especialmente nos distritos de Lisboa e Porto, locais onde a concentração das indústrias foi extremamente relevante numericamente e importante para a economia e cultura nacional. Nesse caso, os trabalhos que antecedem essa publicação são referidos, demonstrando a validade de cada um e de que forma essas investigações singulares contribuíram para que houvesse um avanço na preservação da história e do patrimônio industrial em Portugal. Sampaio também apresenta o atual cenário do país no que tange à valorização e preservação desse passado industrial, e onde é possível encontrar instituições que visam a salvaguarda dessa memória.

Maria Sampaio demonstra que os vestígios móveis possuem uma grande facilidade de perda, pois os objetos industriais são aqueles que mais facilmente são perdidos no processo de abandono e desvalorização do patrimônio. Enquanto cimento e tijolos perduram por mais tempo, os objetos móveis são facilmente depredados, furtados e, assim, desaparecem (p. 8). Para isso, Sampaio se debruça em extensa bibliografia sobre cultura material e primordialmente nos conceitos de biografia cultural das coisas de Igor Kopytoff (2008) e ciclo de vida de Karin Dannehl (2009). É no decorrer do segundo capítulo (p. 67-112) que a autora descreve de que forma a cultura material passou a ser valorizada enquanto fonte, e como o estudo dos objetos permite compreender desde o momento de produção do produto, consumo, até o fim da sua vida e sua musealização.

Esse é um aspecto singular na referida obra, pois a proposta da autora integra discussões historiográficas sobre a temática do patrimônio, colocando sempre em destaque a sua problemática principal: o patrimônio técnico-industrial, e, ainda, propõe uma contribuição para a área através de uma abordagem da cultura material, um motor elétrico. Essa investigação tem como palco o Museu da Indústria do Porto, mas proporciona a conexão de outros aspectos, tal como o contexto de surgimento das indústrias de Portugal até a sua desaceleração e deslocalização. Tais discussões são elaboradas no terceiro capítulo (p. 113-211), onde há uma apresentação do surgimento da indústria portuense e das suas fases, bem como os projetos de inventário do patrimônio industrial que acabaram colaborando no surgimento do museu. 
Para Sampaio o projeto de Inventário do Patrimônio Industrial do Porto, ocorrido entre 1992 e 1993, foi de extrema importância para uma conscientização dos pares e da comunidade como um todo para a relevância do seu legado industrial. Além disso, foi esse projeto que inspirou outras iniciativas que puderam se desenvolver, dentre elas exposições, publicitárias e culturais. Essa sequencia de atividades demonstrou que as indústrias estavam muito presentes na identidade e memória do portuense. É nesse contexto que surge a ideia de criação de um Museu da Ciência e da Indústria, instalado na antiga fábrica da Companhia de Moagens Harmonia. Assim, surge um museu voltado especificamente para a preservação dessas memórias e suas materializações na cidade do Porto.

A ideia do museu tinha por intuito dialogar e preservar a história, patrimônio e arqueologia industrial do Porto por meio de atividades expositivas e educativas. Entretanto, em 2006 o museu teve o seu prédio entregue para a construção um estabelecimento hoteleiro, alterando sua constituição. Com dificuldades de preservação do acervo, e a transferência para outros locais, em 2010 houve a dissolução do Museu da Ciência e Indústria, posteriormente dando origem ao Museu da Indústria do Porto. Sampaio apresenta a constituição do acervo do museu, exibindo em gráficos a sua procedência, quais as tipologias de objetos mais presentes, e quais fábricas são representadas no acervo.

O último capítulo (p. 211-327) é dedicado para a análise do motor elétrico do acervo do Museu da Indústria do Porto, marca ASEA. A autora apresenta de forma clara a metodologia utilizada, ao tomar objeto tridimensional enquanto fonte histórica desenvolve questões que indicam não só a sua trajetória, mas o contexto industrial em que está inserido. Com esse objetivo, Sampaio utilizou o método proposto por Marta Lourenço e Samuel Gessner (2014) ao analisarem objetos científicos.

A análise minuciosa feita por Luz Sampaio inclui os aspectos físicos e as camadas invisíveis inerentes ao objeto. $\mathrm{O}$ resultado desenvolvido ao longo do último capítulo demonstra o aprofundamento realizado pela autora, o qual origina um conjunto de informações que extrapola a peça em si. Por outro lado, pelo fato de o motor nunca ter sido exposto ao público o trabalho torna-se ainda mais significativo, visto que ele torna visível e público aquilo que estaria indisponível aos olhares externos. Todos os dados são organizados pela autora em uma ficha e esta serve como exemplo para os pesquisadores da 
área da cultura material, incluindo os que não se atentam especificamente aos objetos técnico-industriais.

Em suma, a recente publicação portuguesa complementa lacunas existentes na área do patrimônio e da arqueologia industrial, sobretudo no Brasil, demonstrando uma capacidade de inovação na área através da interdisciplinaridade. A clareza da metodologia aplicada facilita a utilização da pesquisa como uma referência para as ciências humanas e da informação. A sensibilidade do trabalho possibilita a reflexão sobre a importância da cultura material e, ainda, dá lugar para que uma peça de aparência fria e pouco atraente esteticamente se torne viva e com camadas que conectam tempos e sujeitos.

\section{Referências}

DANNEHL, K. Objects biographies: from the production to consumption. In: DANNEHL, K. History and material culture: a student's guide to approaching alternative sources. London: Routledge, 2009. p. 123-138.

KOPYTOFF, I. A biografia cultural das coisas: a mercantilização como processo. In: APPADURAI, A. A vida social das coisas: as mercadorias sob uma perspectiva cultural. Niterói: EdUFF, 2008. p. 89-121.

LOURENÇO, M.; GESSNER, S. Documenting collections: cornerstones for more history of science museums. Science and Education, v. 23, n. 4, p. 727-745, 2014. 